\title{
Familial congenital palsy of trochlear nerve
}

INSERM

\section{Source}

INSERM. (1999). Orphanet: an online rare disease and orphan drug data base. Familial congenital palsy of trochlear nerve. ORPHA:91498

Familial congenital palsy of trochlear nerve is a rare, genetic, neuro-ophthalmological disease characterized by congenital fourth cranial nerve palsy, manifesting with hypertropia in side gaze, unexplained head tilt, acquired vertical diplopia, and progressive increase in vertical fusional vergence amplitudes with prolonged occlusion. Facial asymmetry (i.e. hemifacial retrusion, upward slanting of mouth on the side of the head tilt, mild enophthalmos of paretic eye) and superior oblique tendon abnormalities (such as absence, redundance, misdirection) are frequently associated. Some asymptomatic cases have been reported. 